\title{
Spontaneous Nicotine Withdrawal Potentiates the Effects of Stress in Rats
}

\author{
Sietse Jonkman ${ }^{1,3,4}$, Victoria B Risbrough ${ }^{1,2,4}$, Mark A Geyer ${ }^{1,2}$ and Athina Markou, ${ }^{*, 1}$ \\ 'Department of Psychiatry, School of Medicine, University of California San Diego, La Jolla, CA, USA; ${ }^{2}$ Veterans Administration Center for Stress \\ and Mental Health, La Jolla, CA, USA
}

\begin{abstract}
Anxiety is a common symptom of nicotine withdrawal in humans, and may predict an inability to abstain from cigarette smoking. It is not clear if self-reports of anxiety during abstinence reflect increased baseline anxiety and/or increased responses to exogenous stressors. We hypothesized that nicotine withdrawal selectively exacerbates reactivity to aversive stimuli in rodents. Here, we investigated the effect of withdrawal from chronic nicotine administration $(3.16 \mathrm{mg} / \mathrm{kg}$ per day base, delivered via subcutaneous osmotic minipumps) in the light-enhanced startle (LES) test in Wistar rats. In this procedure, baseline startle responding in the dark is compared to startle responding when the chamber is brightly lit. Bright illumination is aversive for rats and potentiates the startle response. Hence, this procedure allows comparisons of withdrawal effects on startle reactivity between relatively neutral and stressful contexts. We found that spontaneous nicotine withdrawal ( $24 \mathrm{~h}$ post-pump removal) did not influence baseline startle responding, but produced a selective increase in LES. Precipitated nicotine withdrawal through injections of one of two nicotinic acetylcholine receptor (nAChR) antagonists, dihydro- $\beta$-erythroidine hydrobromide $(\mathrm{DH} \beta \mathrm{E}: 0,1.5,3$, or $6 \mathrm{mg} / \mathrm{kg})$ or mecamylamine $(0,1,2$, or $4 \mathrm{mg} / \mathrm{kg})$, did not influence baseline startle responding or LES. These results suggest that spontaneous nicotine withdrawal selectively potentiates responses to anxiogenic stimuli, but does not by itself produce a strong anxiogenic effect. These findings support the hypothesis that nicotine withdrawal exacerbates stress responding, and indicate LES may be a useful model to examine withdrawal effects on anxiety.

Neuropsychopharmacology (2008) 33, 2 I31-2138; doi:10.1038/sj.npp. I 301607; published online 21 November 2007
\end{abstract}

Keywords: nicotine; withdrawal; anxiety; startle; rat

\section{INTRODUCTION}

Anxiety is one of the symptoms that the Diagnostic and Statistical Manual of Mental Disorders of the American Psychiatric Association lists for the nicotine withdrawal syndrome in humans (American Psychiatric Association, 1994). Self-report studies have generally indicated increased anxiety after cessation of cigarette smoking (Hughes et al, 1991; Zvolensky et al, 2005). Further, increased anxiety during withdrawal has been found to predict an inability to abstain from tobacco smoking (Pomerleau et al, 2005), highlighting the importance of understanding the neuropsychological basis of increased anxiety during cigarette and nicotine withdrawal.

In behavioral rodent experiments, anxiety often is assessed in tests that are based on the conflicting drives to explore novel, potentially rewarding stimuli and environments, and

\footnotetext{
* Correspondence: Dr A Markou, Department of Psychiatry, M/C0603, School of Medicine, University of California, San Diego, 9500 Gilman Drive, La Jolla, CA 92093-0603, USA, Tel: + I 858534 I572, Fax: + I 858534 99|7, E-mail: amarkou@ucsd.edu

${ }^{3}$ Present address: Department of Experimental Psychology, University of Cambridge, Cambridge, UK.

${ }^{4}$ These authors contributed equally to this work.

Received 30 July 2007; revised 26 September 2007; accepted 27 September 2007
}

avoid potentially threatening conditions. Using such tests, it has been shown that withdrawal from chronic nicotine administration leads to anxiogenic-like effects in the lightdark box and elevated plus maze tests in DBA/2J and C57BL/6J mice (Costall et al, 1989; Jonkman et al, 2005; Damaj et al, 2003) and the elevated plus maze and social interaction test in rats (Irvine et al, 2001; Pandey et al, 2001; Cheeta et al, 2001). Thus, nicotine withdrawal is associated with an anxiogenic-like effect in exploration-based tests in rodents, at least in relatively high stress environments (eg novelty, bright light, open spaces).

In addition to conflict-based models of anxiety, there is a class of anxiety tests that assesses passive reflex reactivity and does not involve measures of exploratory behavior or a conflict situation. These tests rely on the phenomenon that the acoustic startle response is augmented during threat in mammals (Brown et al, 1951; Davis, 1998). Startle reactivity has been shown to be increased during presentation of conditioned and unconditioned aversive stimuli, such as a shock-paired cue light and foot shock (Davis et al, 1989; Davis, 1989), and after presentation of more ethologically threatening stimuli, such as bright illumination and predator odor (Walker and Davis, 1997; Hebb et al, 2003). With such startle-based tests, it has been shown that defensive behavior can be dissociated phenomenologically and anatomically into a fast onset, fast offset response 
system to specific threats, and a slow onset, slow offset response system to potential and unpredictable threats (Walker et al, 2003). The former system, referred to as the fear system, is critically dependent on the integrity of the central nucleus of the amygdala, and can be modeled with cueenhanced startle. The latter system, referred to as the anxiety system, is critically dependent on the integrity of the bed nucleus of the stria terminalis (BNST), and can be modeled with light-enhanced startle (LES) and corticotropin-releasing factor (CRF) administration (Walker and Davis, 1997; de Jongh et al, 2003). Because startle reactivity is a cross-species defensive behavior that has translational value for understanding the mechanisms of anxiety (Risbrough and Stein, 2006), this test could provide important information on how nicotine withdrawal affects anxiety systems.

Several studies have examined the effect of nicotine withdrawal on baseline startle amplitudes. Unfortunately, the results of these studies have been inconsistent. It has been reported that startle amplitudes were unchanged during nicotine withdrawal in DBA/2J and C57BL/6J mice (Semenova et al, 2003, Jonkman et al, 2005) and SpragueDawley, Wistar, and Long-Evans rats (Acri et al, 1991, 1995), while increases in startle amplitude have been reported in Long-Evans rats (Helton et al, 1993, 1997; Rasmussen et al, 1996, 1997, 2000). Interestingly, however, the studies that showed increases in startle amplitudes during nicotine withdrawal tested subjects for startle reactivity in ambient lighting conditions (Kurt Rasmussen, personal communication), suggesting that perhaps the presence of anxiogenic illumination may be a critical factor in the effect of nicotine withdrawal on startle reactivity. Importantly, the effects of nicotine withdrawal on baseline startle reactivity cannot be ascribed to any specific psychological process such as anxiety because a wide variety of manipulations, some of them putatively orthogonal to anxiety mechanisms (eg strychnine-induced startle), may increase the brainstem acoustic startle response (Koch, 1999).

In contrast, the LES test allows the investigation of the effects of nicotine withdrawal on anxiety-related processes. LES involves the measurement of a reactive response in a stressful situation. In this procedure, startle responses are measured in successive sessions during which the startle chambers are either dark or brightly lit. The startle response is potentiated by the aversive bright light in a slow onset, slow offset manner, and this response is selectively reduced by anxiolytic compounds (de Jongh et al, 2002; Walker and Davis, 2002). Hence, the degree to which light enhances startle reactivity is used as an operational measure of anxiety.

In the present study, we investigated the potential anxiogenic effects of withdrawal from chronic nicotine administration in the LES test in Wistar rats. We hypothesized that both spontaneous and precipitated nicotine withdrawal would specifically enhance the aversive effect of light-potentiating startle reactivity in light, but not dark, testing conditions.

\section{METHODS}

\section{Animals}

Male Wistar rats (Charles River, Raleigh, NC) were housed in groups of two. Food and water were available ad libitum in the home cages. All rats were kept on a 12-h reverse light/ dark cycle (lights off from 0700 to 1900) in a colony room with temperature and humidity remaining constant. On testing days, animals were transferred from the animal facility in transparent individual holding cages and placed in a dark and quiet room for at least $60 \mathrm{~min}$ prior to the beginning of testing.

\section{Apparatus}

Rats were placed in cylindrical Plexiglas chambers mounted on a Plexiglas platform inside a ventilated, sound-attenuated chamber (San Diego Instruments, San Diego, CA, USA). A high-frequency loudspeaker was located directly above the cylindrical Plexiglas chamber housing the rat. Measurement of the startle response is described in detail elsewhere (Mansbach et al, 1988). Briefly, the flinch response of the animal was measured using a piezoelectric unit mounted at the bottom of the platform, which sends a digitized signal to the computer. Monthly calibration was performed on the chambers to ensure the accuracy of the sound levels and measurements. Each startle apparatus was equipped with a compact fluorescent light bulb (Commercial Electric, Model no. EDXO-23) inside the soundattenuating chamber that produced light intensities between 2700 and $3600 \mathrm{~lx}$ measured inside the Plexiglas cylinder using a Minolta Auto meter IV F luxmeter.

\section{Drugs}

Nicotine hydrogen tartrate salt and mecamylamine hydrochloride were purchased from Sigma Chemical Co. (St Louis, MO) and dihydro- $\beta$-erythroidine hydrobromide $(\mathrm{DH} \beta \mathrm{E})$ was purchased from Research Biochemicals (Natick, MA). All drugs were dissolved in physiological saline ( $0.9 \%$ sodium chloride). Nicotine was delivered subcutaneously (s.c.) through implantation of an osmotic minipump, whereas mecamylamine and $\mathrm{DH} \beta \mathrm{E}$ were injected intraperitoneally (i.p.) in a volume of $1 \mathrm{ml} / \mathrm{kg}$ body weight. Nicotine doses are reported as base, and nicotinic receptor antagonist doses are reported as salt.

\section{Surgeries}

Osmotic minipumps (Alzet model 2ML4 28 day pumps, Alza Corporation, Palo Alto, CA) filled with either saline or nicotine hydrogen tartrate dissolved in saline were implanted s.c. under isoflurane/oxygen (1-3\% isoflurane) anesthesia. The nicotine concentration was adjusted based on the body weight of animals to deliver an average dose of $3.16 \mathrm{mg} / \mathrm{kg}$ per day nicotine base $(9 \mathrm{mg} / \mathrm{kg}$ per day nicotine tartrate).

\section{Light-Enhanced Startle}

The LES procedures were based on those of de Jongh et al (2005). One LES measurement was based on four startle tests (termed blocks), which were conducted in two separate sessions of two blocks each. At the beginning of the startle tests (block 1 of the session), the rats were placed in the startle chamber and left undisturbed in the dark for $5 \mathrm{~min}$. Thereafter, the rats were presented with 30 startle stimuli, 10 each at 90,95, and $105 \mathrm{~dB}$, with an average interstimulus 
interval of $30 \mathrm{~s}$, presented in a pseudorandom order and in dark conditions. These 30 stimuli constituted the first startle block. After the first block, the rats were removed from the chamber and placed in their holding cage in an adjacent dark and quiet room for $5 \mathrm{~min}$ (spontaneous withdrawal experiment) or $15 \mathrm{~min}$ (precipitated withdrawal experiments). After this interval, rats were placed back into the startle chambers for the second block of the session, which was exactly the same as the first block, except that it was presented either in the dark (dark $\rightarrow$ dark session) or bright light (dark $\rightarrow$ light session) condition. Thus, one full test of LES consisted of two separate test sessions, one dark $\rightarrow$ dark to measure habituation of the startle reflex, and one dark $\rightarrow$ light to measure the startle-enhancing effects of the light. The rats were tested with at least $48 \mathrm{~h}$ between these two sessions for the precipitated withdrawal experiments, or on the same day at least $6 \mathrm{~h}$ apart for the spontaneous withdrawal experiment. The order of sessions (block 2 in either the dark or light condition) was counterbalanced across animals within groups. That is, half of the rats started the experiment with a dark $\rightarrow$ dark session, and the other half began with a dark $\rightarrow$ light session. For precipitated withdrawal experiments, nicotinic receptor antagonists were injected immediately after the first block because of concerns that injection before the first block may have resulted in a reduced precipitated nicotine withdrawal state by the time the critical second block of the session started, due to dissipation of the drug. To this end, the interval between block 1 and block 2 in precipitated nicotine withdrawal experiments was extended to $15 \mathrm{~min}$ to allow distribution of the administered nicotinic acetylcholine receptor (nAChR) antagonists in the central nervous system before initiation of the second block.

\section{Experimental Design}

Prior to implantation of minipumps, all rats were given one startle session in which the light was on in the second block. Rats were then assigned to nicotine and saline pump conditions so that they were counterbalanced for both average peak startle value in the first block (baseline startle in the dark) and percentage increase of startle value in the second block (LES). The minipumps were implanted, and the rats were left undisturbed for at least 7 days before the first precipitated nicotine withdrawal test to allow nicotine 'dependence' to develop. Previous studies indicate that 6 days of nicotine exposure is sufficient to allow the detection of precipitated nicotine withdrawal effects on intracranial selfstimulation thresholds upon administration of nAChR antagonists (eg Bruijnzeel and Markou, 2004; Skjei and Markou, 2003). The minipumps were surgically removed 28 days after implantation, and spontaneous nicotine/saline withdrawal was assessed in the LES test $24 \mathrm{~h}$ after minipump removal.

The results reported here are derived from three experiments that were conducted sequentially. Naive rats were used in each of the three experiments. In the first experiment, saline- $(n=5)$ and nicotine-treated $(n=5)$ rats were left undisturbed for 28 days until the pumps were removed, and spontaneous nicotine withdrawal was assessed 20-28 h later with one dark $\rightarrow$ dark and one dark $\rightarrow$ light session conducted at least $6 \mathrm{~h}$ apart.
In the second experiment, a separate group of naive rats was treated with saline $(n=10)$ or nicotine $(n=10)$ for 28 days and tested for $\mathrm{DH} \beta \mathrm{E}$-precipitated nicotine withdrawal in the LES test, while the rats were treated with nicotine or saline via the subcutaneous osmotic minipumps that were removed on day 28 of pump exposure after the completion of $\mathrm{DH} \beta \mathrm{E}$ testing. $\mathrm{DH} \beta \mathrm{E}$ was injected immediately after the first block of the session, and the rats were left undisturbed for $15 \mathrm{~min}$ before the second block commenced. The effects of $\mathrm{DH} \beta \mathrm{E}$ on LES in saline- and nicotine-treated rats were assessed using a within-subjects pseudorandom design, where each rat received i.p. injections of saline, $1.5,3$, and $6 \mathrm{mg} / \mathrm{kg}$ $\mathrm{DH} \beta \mathrm{E}$ with a washout period of at least $48 \mathrm{~h}$ between each injection. This procedure resulted in a total of eight injections, administered in four dark $\rightarrow$ dark and four dark $\rightarrow$ light sessions, all conducted at least $48 \mathrm{~h}$ apart. The $\mathrm{DH} \beta \mathrm{E}$ injections were administered between days 7 and 24 of saline/nicotine exposure. Previous work has indicated that these conditions result in reliable precipitated nicotine withdrawal, as assessed by elevations in intracranial self-stimulation thresholds (Epping-Jordan et al, 1998; Skjei and Markou, 2003; Watkins et $a l, 2000)$. The minipumps were removed 28 days after implantation, and spontaneous nicotine withdrawal was assessed 20-28 h later with one dark $\rightarrow$ dark and one dark $\rightarrow$ light session conducted at least $6 \mathrm{~h}$ apart. Previous work has indicated that such nicotine exposure results in reliable and robust spontaneous nicotine withdrawal as assessed by both elevations in intracranial self-stimulation thresholds and somatic signs of withdrawal (Skjei and Markou, 2003).

In the third experiment, a separate set of naive rats was treated with saline $(n=12)$ or nicotine $(n=10)$ for 28 days and tested for mecamylamine-precipitated nicotine withdrawal in the LES test, while the rats were treated with nicotine or saline via the subcutaneous osmotic minipumps that were removed on day 28 of pump exposure after the completion of mecamylamine testing. Mecamylamine was injected immediately after the first block of the session, and the rats were left undisturbed for $15 \mathrm{~min}$ before the second block commenced. The effects of mecamylamine on LES in saline- and nicotine-treated rats were assessed using a within-subjects pseudorandom design, where each rat received i.p. injections of saline, 1,2 , and $4 \mathrm{mg} / \mathrm{kg}$ mecamylamine with a washout period of at least $48 \mathrm{~h}$ between each injection. This procedure resulted in a total of eight injections, administered in four dark $\rightarrow$ dark and four dark $\rightarrow$ light sessions, all conducted at least $48 \mathrm{~h}$ apart. The mecamylamine injections were administered between days 7 and 24 of saline/ nicotine exposure. The pumps were removed 28 days after implantation, and spontaneous nicotine withdrawal was assessed 20-28 h later with one dark $\rightarrow$ dark and one dark $\rightarrow$ light session conducted at least $6 \mathrm{~h}$ apart.

The spontaneous nicotine withdrawal data from these three experiments were pooled. Rats that showed mild signs of unhealed or open post-pump removal incisions before spontaneous withdrawal testing were excluded from the spontaneous withdrawal analyses, yielding a total of 25 saline-treated and 24 nicotine-treated rats.

\section{Statistical Analyses}

The effect of spontaneous nicotine withdrawal on baseline startle values was analyzed with an analysis of variance 
(ANOVA) with Nicotine (nicotine- or saline-containing pump) as a between-subjects factor, and Session (Dark $\rightarrow$ Dark or Dark $\rightarrow$ Light) and Block (first or second) as withinsubjects factors. Due to consistent interactions of pulse intensity with the other factors, data for the three startle pulse intensities were subsequently analyzed separately. To assess the effect of spontaneous nicotine withdrawal on LES, a difference score of the peak startle value was calculated for each session (Dark $\rightarrow$ Dark and Dark $\rightarrow$ Light). This difference score was calculated by subtracting the startle value of the first block from that of the second block. The difference scores were analyzed with an ANOVA with Nicotine/Saline as the between-subject factor and Session as the withinsubjects factor.

The effects of nicotinic receptor antagonist-precipitated nicotine withdrawal on baseline startle values were assessed by analyzing data from the second block only because the nicotinic antagonists were injected after the first block, before assessment in the second startle block. The data were analyzed with an ANOVA with Nicotine/Saline treatment (ie pump content) as the between-subjects factor, and Dose (separate analyses for $\mathrm{DH} \beta \mathrm{E}$ and mecamylamine experiments) and Session as the within-subjects factors. Statistically significant interactions were further analyzed with Tukey's post hoc comparisons. The criterion for significance was set at $p<0.05$.

\section{RESULTS}

\section{Spontaneous Nicotine Withdrawal}

Twenty-four hours after pump removal, baseline startle levels were not altered (Nicotine/Saline: $\mathrm{F}_{1,47}<1$, NS). There was a significant Session $\times$ Block interaction $\left(\mathrm{F}_{1,47}=17.04\right.$, $p<0.001$ ), indicating that startle was indeed significantly potentiated during the light session across all groups. However, there was also a significant Session $\times$ Block $\times$ Pulse intensity interaction $\left(\mathrm{F}_{2,94}=13.57, \quad p<0.001\right)$. Subsequent separate analyses of the three pulse intensity startle values revealed that LES was only significant at the highest startle intensity $(105 \mathrm{~dB})$ across both treatment groups (Session $\times$ Block: $90 \mathrm{~dB}: \mathrm{F}_{1,47}=3.49$, NS; $95 \mathrm{~dB}$ : $\mathrm{F}_{1,47}=3.97$, NS; $105 \mathrm{~dB}: \mathrm{F}_{1,47}=17.02, p<0.001$; Table 1). Thus, subsequent analyses of the effect of Nicotine/Saline withdrawal on LES were conducted using only the $105 \mathrm{~dB}$ startle data. Analysis of the $105 \mathrm{~dB}$ pulse data revealed no significant effect of Nicotine/Saline withdrawal on baseline startle values $\left(\mathrm{F}_{1,47}<1\right.$, ns; Figure 1). However, Nicotine/ Saline treatment did interact with the light/dark condition (Nicotine $\times$ Session $\times$ Block: $\mathrm{F}_{1,47}=6.06, p<0.025$, Figure 1 ), indicating that nicotine withdrawal significantly potentiated LES. Hence, there was a light-potentiated startle effect in the $105 \mathrm{~dB}$ pulse data, and this effect was significantly increased by nicotine withdrawal.

Analysis of the difference scores for the $105 \mathrm{~dB}$ startle values subsequently confirmed that there was a significant overall effect of the light condition on startle reactivity, which was significantly enhanced in the nicotine-withdrawing group (Session: $\mathrm{F}_{1,47}=17.02, p<0.001$; Session $\times$ Nicotine: $F_{1,47}=6.06, p<0.025$; Figure 2). Posthoc analysis with Tukey's test revealed that this interaction reflected a significant increase in difference scores during nicotine withdrawal in the Dark $\rightarrow$ Light (Nicotine/Saline: $\left.\mathrm{F}_{1,47}=8.86, p<0.01\right)$, but not the Dark $\rightarrow$ Dark session (Nicotine: $F_{1,47}<1$, NS). Thus, nicotine withdrawal selectively increased startle during the light sessions.

There was no main effect of order of session presentation (dark-dark $v s$ dark-light) on LES, nor was there an interaction of that factor with Nicotine/Saline $\left(\mathrm{F}_{1,45}=2.11\right.$, NS). We did observe a main effect of rat cohort (data were pooled from three different startle experiments) on overall startle reactivity $\left(\mathrm{F}_{2,37}=6.27, p<0.01\right)$, due to the initial nicotine group from the first experiment exhibiting lower baseline startle than the $\mathrm{DH} \beta \mathrm{E}-$ or mecamylamine-treated cohorts $(p<0.05$, Tukey's test). There was no interaction, however, of rat cohort with Session, Phase, or Nicotine/Saline (data not shown), supporting the combination of the spontaneous withdrawal data from the three rat cohorts to examine the effects of nicotine withdrawal on LES.

\section{Precipitated Nicotine Withdrawal}

$D H \beta E$. Startle values and difference scores were only analyzed for the $105 \mathrm{~dB}$ pulse data, because, as mentioned above, the 90 and $95 \mathrm{~dB}$ pulse intensities did not consistently produce LES. The $105 \mathrm{~dB}$ peak startle values were neither affected by chronic nicotine administration

Table I Light-Enhanced Startle in Wistar Rats Across the Three Startle Pulse Intensities Used in the Present Studies

\begin{tabular}{|c|c|c|c|c|c|}
\hline Pulse (dB) & Condition & Dark I.I & Dark I.2 & Dark 2.I & Light 2.2 \\
\hline \multirow[t]{2}{*}{90} & Saline & $95.5( \pm 30.5)$ & $101.1( \pm 34.6)$ & $80.4( \pm 20.4)$ & $138.7( \pm 26.4)$ \\
\hline & Nicotine & $115.6( \pm 20.2)$ & $120.0( \pm 27.6)$ & $126.5( \pm 24.3)$ & $167.3( \pm 26.4)$ \\
\hline 95 & Nicotine & $373.4( \pm 64.1)$ & $466.9( \pm 92.1)$ & $394.0( \pm 51.4)$ & $570.5( \pm 78.6)$ \\
\hline 105 & Saline & | $674.8( \pm$ | 45.7$)$ & | $842.7( \pm$ | 68.5$)$ & $1804.5( \pm 151.9)$ & $2195.8( \pm 169.3)$ \\
\hline
\end{tabular}

Rats were administered saline or $3.16 \mathrm{mg} / \mathrm{kg}$ per day of nicotine (base) and tested for LES $24 \mathrm{~h}$ after removal of the osmotic minipumps. The LES test consists of one session with two consecutive startle blocks in the dark (Dark I.I and Dark I.2) and a second session with two consecutive startle blocks with a bright light turned on in the second block (Dark 2.I and Light 2.2). Mean peak startle responses ( \pm SEM) are presented. There was a significant interaction between Session and Block, reflecting LES, and this effect interacted with Pulse intensity. Subsequent analyses revealed that there was a significant LES effect in the $105 \mathrm{~dB}$, but not the $90 \mathrm{~dB}$ or $95 \mathrm{~dB}$, pulse data. There was no effect of spontaneous nicotine withdrawal on baseline startle in any group. Group sizes were nicotine $(n=24)$ and saline $(n=25)$. 


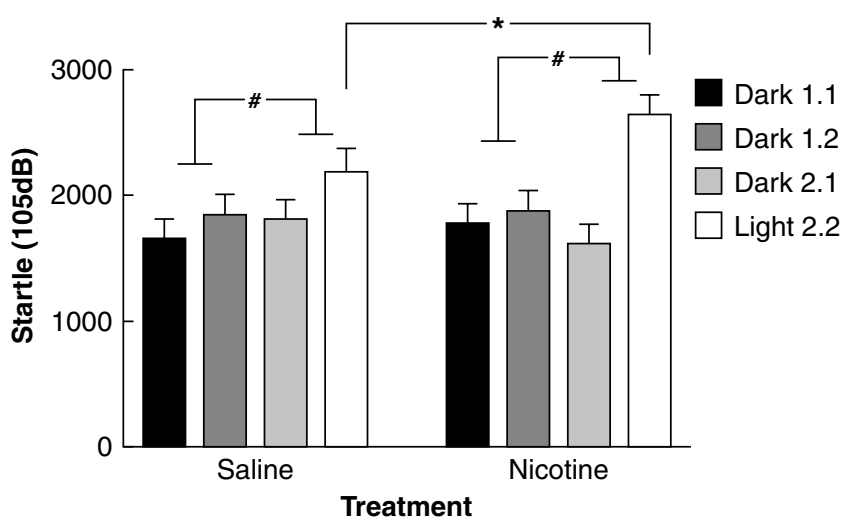

Figure I Effects of spontaneous nicotine withdrawal on baseline peak startle and LES in Wistar rats for $105 \mathrm{~dB}$ startle pulse data. Data are mean \pm SEM peak startle response. Rats were administered saline or $3.16 \mathrm{mg} / \mathrm{kg}$ per day of nicotine (base) for 28 days, and tested in the LES $24 \mathrm{~h}$ after removal of the nicotine/saline-containing minipump. The LES test consists of one session with two consecutive startle blocks in the dark (Dark I.I and Dark I.2) and a second session with two consecutive startle blocks with a bright light turned on in the second block (Dark 2.1 and Light 2.2). There was no effect of nicotine withdrawal on baseline startle. There was a significant LES effect on startle reactivity to the $105 \mathrm{~dB}$ pulse, and nicotine withdrawal significantly potentiated this LES effect. Asterisk $(* 0<0.025)$ indicates a significant effect of nicotine withdrawal on LES. Hash $(\# p<0.001)$ indicates a significant light-enhanced startle effect. Group sizes were nicotine $(n=24)$ and saline $(n=25)$.

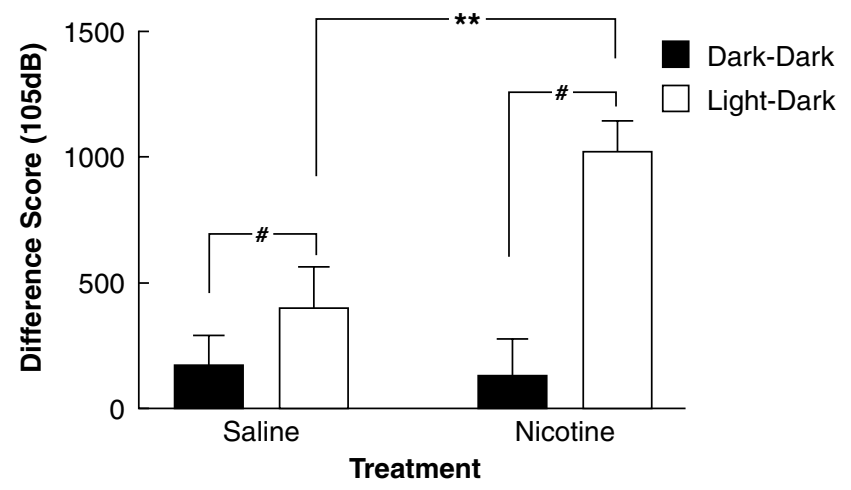

Figure 2 Effect of spontaneous nicotine withdrawal on difference scores of peak startle response to a $105 \mathrm{~dB}$ stimulus between the dark and the light session in Wistar rats. Rats were administered saline or $3.16 \mathrm{mg} / \mathrm{kg}$ per day nicotine (base) for 28 days and tested $24 \mathrm{~h}$ after removal of the minipump. The difference scores were calculated by subtracting the average peak startle response in the first block from that in the second block for both sessions, yielding average Dark 1.2-Dark I.I (session I) and Light 2.2-Dark 2.I (session 2) difference scores ( \pm SEM). There was a main effect of Session (reflecting LES) and an interaction between Nicotine/ Saline withdrawal and Session that was due to a specific increase in the light-dark (but not dark-dark) difference scores by nicotine withdrawal. Asterisks $(* * 0.01)$ indicate a significant increase in light-dark difference scores associated with nicotine withdrawal. Hash $(\# p<0.00 \mathrm{I})$ indicates a significant light-enhanced startle effect. Group sizes were nicotine $(n=24)$ and saline $(n=25)$.

$\left(\mathrm{F}_{1,18}<1\right.$, NS, Figure 3$)$ nor $\mathrm{DH} \beta \mathrm{E}$ injections $\left(\mathrm{F}_{3,54}=1.23\right.$, NS). Further, there was no interaction of the factors Nicotine/Saline and $\mathrm{DH} \beta \mathrm{E}$ dose $\left(\mathrm{F}_{3,54}<1, \mathrm{NS}\right)$. There was a significant effect of Session, reflecting LES $\left(\mathrm{F}_{1,18}=40.95\right.$, $p<0.001)$, but this effect did not interact significantly with chronic Nicotine/Saline administration $\left(\mathrm{F}_{1,18}=1.91, \mathrm{NS}\right)$ or

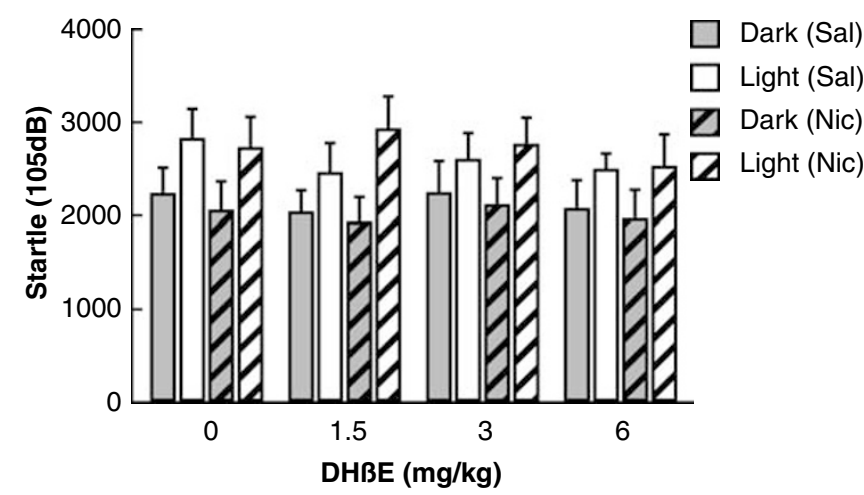

Figure 3 Effect of dihydro- $\beta$-erythroidine hydrobromide $(\mathrm{DH} \beta \mathrm{E})$ precipitated nicotine withdrawal on peak startle reactivity to a $105 \mathrm{~dB}$ startle pulse in Wistar rats exposed through osmotic minipumps to saline or $3.16 \mathrm{mg} / \mathrm{kg}$ per day nicotine (base). $\mathrm{DH} \beta \mathrm{E}$ (within-subjects Latin square, saline, $1.5,3$, and $6 \mathrm{mg} / \mathrm{kg}$ ) was injected intraperitoneally immediately after the first block of the session and the second block commenced 15 min later. Subcutaneous minipumps delivering saline or nicotine were present throughout the $\mathrm{DH} \beta \mathrm{E}$ experiment (see the 'Methods' section for details). The startle values depicted are averages of the second (post-injection) block $( \pm \mathrm{SEM})$. DH $\beta \mathrm{E}$ did not affect baseline startle or LES differentially between nicotine- and saline-treated rats. Group sizes were nicotine $(n=10)$ and saline $(n=10)$.

$\mathrm{DH} \beta \mathrm{E}$ injections $\left(\mathrm{F}_{3,54}<1, \mathrm{NS}\right)$. Further, there was no three-way interaction between the factors Session, Nicotine/ Saline, and $\mathrm{DH} \beta \mathrm{E}$ dose $\left(\mathrm{F}_{3,54}<1, \mathrm{NS}\right)$. Finally, there was no effect of order of testing $\left(\mathrm{F}_{3,54}<1, \mathrm{NS}\right)$, and no interaction of order of testing with Nicotine/Saline exposure or $\mathrm{DH} \beta \mathrm{E} /$ saline injections $\left(\mathrm{F}_{3,54}<1, \mathrm{NS}\right)$. Thus, $\mathrm{DH} \beta$ E-precipitated nicotine withdrawal did not increase LES.

Mecamylamine. As previously stated, startle values and difference scores were only analyzed for the $105 \mathrm{~dB}$ pulse data. The $105 \mathrm{~dB}$ peak startle values were significantly affected by mecamylamine injections $\left(\mathrm{F}_{3,60}=3.01, p<0.05\right)$, but this effect did not interact with Session $\left(\mathrm{F}_{3,60}=2.73\right.$, NS), reflecting a general suppressive effect of mecamylamine on startle. Startle reactivity was reduced during both the dark and light blocks (Figure 4). The effect of mecamylamine injections did not interact with chronic Nicotine/Saline administration $\left(\mathrm{F}_{3,60}<1, \mathrm{NS}\right)$. There was a significant effect of Session, reflecting LES $\left(\mathrm{F}_{1,20}=28.66\right.$, $p<0.001$ ), but this effect did not interact significantly with chronic Nicotine/Saline administration and Mecamylamine injections (Session $\times$ Nicotine $\times$ Dose: $F_{3,60}=1.44$, NS). Finally, there was no effect of order of testing $\left(\mathrm{F}_{3,60}<1\right.$, NS), and no interaction of order of testing with Nicotine/ Saline exposure and Mecamylamine/Saline injections $\left(\mathrm{F}_{3,60}=1.10\right.$, NS). Thus, mecamylamine-precipitated nicotine withdrawal did not increase LES. Mecamylamine had a general suppressive effect on startle magnitudes that did not interact with Nicotine/Saline treatment or LES.

\section{DISCUSSION}

The present results show that spontaneous nicotine withdrawal significantly increases startle reactivity during light stress, but has no effect on baseline startle responding 


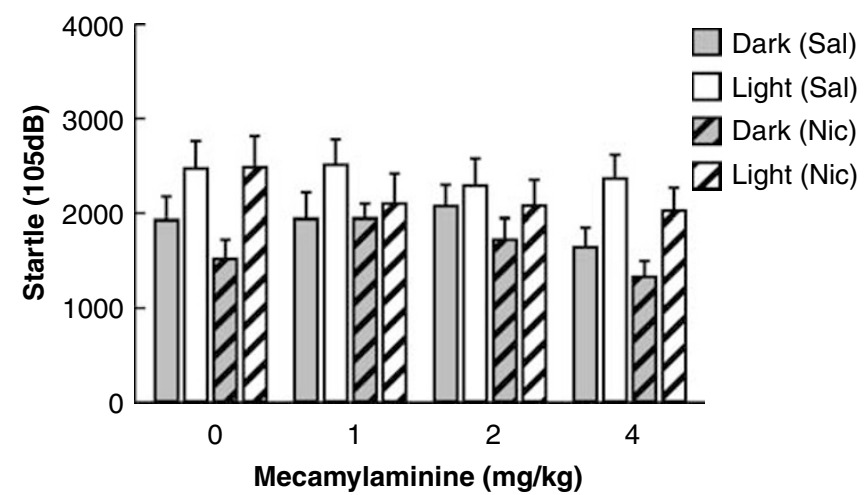

Figure 4 Effect of mecamylamine-precipitated nicotine withdrawal on peak startle reactivity to a $105 \mathrm{~dB}$ startle pulse in Wistar rats exposed through osmotic minipumps to saline or $3.16 \mathrm{mg} / \mathrm{kg}$ per day nicotine (base). Mecamylamine (within-subjects Latin square, saline, I, 2, and $4 \mathrm{mg} / \mathrm{kg}$ ) was injected intraperitoneally immediately after the first block of a session, and the second block commenced 15 min later. Subcutaneous minipumps delivering saline or nicotine were present throughtout the mecanylamine experiment (see the 'Methods' section for details). The startle values depicted are averages of the second (post-injection) block ( \pm SEM). Mecamylamine did not affect baseline startle or LES differentially between nicotine- and saline-treated rats. Mecamylamine induced a significant decrease in startle values that was independent of session (Dark or Light) and Nicotine/Saline withdrawal. Group sizes were nicotine $(n=10)$ and saline $(n=12)$.

measured in dark conditions. This result suggests that nicotine withdrawal does not induce anxiety levels similar to those induced by the presence of aversive bright light or intracerebroventricular administration of CRF (Walker et al, 2003), conditions that increase baseline startle responsivity. Instead, nicotine withdrawal appears to selectively increase anxiety-like reactivity in an aversive environment (ie brightly lit environment) in rats.

An important distinction of the presently used procedure of light-potentiated startle compared to previously used conflict tests is that the LES paradigm provides an internal baseline (startle reactivity during the dark block) to determine the specificity of the experimental manipulation to anxiety-like responding. The present data indicate that nicotine withdrawal affected anxiety responding only in the presence of another stressor, which corresponds well to smoking cessation findings in humans. Specifically, nicotine-withdrawing smokers report increased craving, negative affect symptoms, and somatic symptoms when presented with stressful stimuli (Beckham et al, 1996). Most importantly, low-state anxiety levels are poor predictors of craving and withdrawal in smokers, while highstate anxiety levels are closely linked to these measures (Pomerleau et al, 1990; Perkins and Grobe, 1992; for review see al'Absi, 2006). These data support the notion that behavioral and physiological signs of stress that show exacerbation with nicotine withdrawal may provide predictive screens for smoking cessation treatments.

The finding that nicotine withdrawal does not increase startle responsivity when assessed in the dark is in agreement with reports of unchanged startle during spontaneous nicotine withdrawal in DBA/2J and C57BL/6J mice (Semenova et al, 2003; Jonkman et al, 2005), and Sprague-Dawley, Wistar, and Long-Evans rats (Acri et al, 1991, 1995), though increases have been reported in
Long-Evans rats (Helton et al, 1993, 1997; Rasmussen et al, 1996, 1997, 2000). Interestingly, however, the studies that reported increases in baseline startle reactivity were conducted in transparent startle testing boxes that allowed ample white room light to enter (Kurt Rasmussen, personal communication). Thus, the conditions in the previously published experiments that reported increases in startle reactivity during spontaneous nicotine withdrawal are more similar to our LES conditions, where we did observe increases in startle amplitude, than our standard startle testing in the dark where we did not observe increases in startle during spontaneous nicotine withdrawal. Consequently, the present set of results may have resolved a long-standing discrepancy in the literature about increases or lack of changes in startle reactivity during nicotine withdrawal in rodents. Together with reports of increases in anxiety-like behavior during nicotine withdrawal in various conflict-based models of anxiety (Costall et al, 1989; Jonkman et al, 2005; Damaj et al, 2003; Irvine et al, 2001; Pandey et al, 2001; Cheeta et al, 2001), these results indicate that nicotine withdrawal increases anxietylike behavior during stress (eg novelty, bright light). The present results are one of the first demonstrations that nicotine withdrawal increases anxiety-like reactivity in a nonlocomotor-based measure.

The lack of effect of nAChR antagonists on LES was surprising. It has been well documented that the administration of these nicotinic receptor antagonists to nicotinetreated animals precipitates a depression-like anhedonic effect (ie elevations in intracranial self-stimulation thresholds; Epping-Jordan et al, 1998; Watkins et al, 2000; Skjei and Markou, 2003), and somatic signs of nicotine withdrawal in the case of mecamylamine (Watkins et al, 2000; Malin et al, 1992, 1994) and hyperalgesia (Damaj et al, 2003), similar to that observed during spontaneous nicotine withdrawal. One possible explanation for these findings is that the doses of mecamylamine and $\mathrm{DH} \beta \mathrm{E}$ administered were not high enough to precipitate the increase in anxietylike reactivity seen in spontaneous withdrawal. However, this explanation is unlikely. Both the depression-like and somatic behavioral effects of spontaneous nicotine withdrawal are precipitated in rats with mecamylamine or $\mathrm{DH} \beta \mathrm{E}$ doses that are lower than the highest doses used in the present study (Epping-Jordan et al, 1998; Watkins et al, 2000; Hildebrand et al, 1997; Malin et al, 1994). It is also possible that antagonist precipitated withdrawal was not observed because of the multiple repeated nAchR antagonist-precipitated withdrawals experienced and the shorter exposure to nicotine than in the spontaneous withdrawal experiment; these conditions may not have allowed for neuroadaptive changes to nicotine exposure to occur that may mediate the increased sensitivity of nicotine-exposed animals to the stress of light. Another interpretation is that the increase in anxiety-like behavior observed after spontaneous withdrawal may be mediated by nicotine acetylcholine receptor subtypes other than the $\alpha 4 \beta 2 \mathrm{nAChR}$ subtype for which $\mathrm{DH} \beta \mathrm{E}$ has the highest selectivity (Harvey and Luetje, 1996), and $\beta 4$-containing nicotinic receptors for which mecamylamine shows some limited selectivity (Chavez-Noriega et al, 1997; Papke et al, 2001; although it should be emphasized that generally mecamylamine is nonselective) such as the $\alpha 7$ homomeric nAChR subtype. 
Alternatively, the increase in anxiety-like reactivity that we observed may not have arisen immediately after cessation of nicotine administration. Spontaneous and precipitated nicotine withdrawal both induce reduced activation of nAChRs, but they differ markedly in the time course that elapses between the initial decrease in nAChR activation and behavioral testing. In nicotinic receptor antagonist-precipitated nicotine withdrawal, receptor blockade is immediate. Due to drug metabolism, this blockade may dissipate before downstream effects of such antagonism take effect. Thus, the observed increases in anxiety-like behavior only during spontaneous, but not precipitated, nicotine withdrawal may be attributable to downstream consequences of reduced nicotinic activation that affect anxiety-like behavior. Indeed, it was recently reported that the intracranial self-stimulation threshold elevations observed during immediate precipitated withdrawal were reversible by a CRF receptor antagonist, while the same threshold elevations observed during later spontaneous withdrawal were not reversible by the same CRF receptor antagonist (Bruijnzeel et al, 2007). These findings suggest that the induction of nicotine withdrawal by blockade of nAChRs depends on CRF receptor activation, while the more prolonged spontaneous nicotine withdrawal phase is sustained by downstream consequences that are no longer immediately dependent on CRF receptor activation.

Because the LES effect depends critically on the integrity of the BNST (Walker and Davis, 1997), and given the receptor antagonist-precipitated, but not spontaneous, nicotine withdrawal dependence on CRF mechanisms (Bruijnzeel et al, 2007), enhanced LES may be a downstream consequence of CRF receptor activation. Interestingly, increased norepinephrine release after CRF administration is observed after substantial delays (Palamarchouk et al, 2002), and the administration of clonidine, which reduces norepinephrine release by acting as an agonist at presynaptic inhibitory $\alpha_{2}$ receptor (Pudovkina et al, 2001) and is used as an aid for smoking cessation (Frishman, 2007), into the BNST abolishes the LES effect under baseline conditions (ie no nicotine withdrawal; Schweimer et al, 2005). Therefore, we speculate that CRF may be released during early nicotine withdrawal, which could lead to a delayed norepinephrine effect, which may in turn potentiate LES. These hypotheses deserve further study.

In summary, we show here that nicotine withdrawal modulates the effectiveness of an anxiogenic stimulus, without affecting baseline startle reactivity in Wistar rats. These results suggest that smokers who plan to quit smoking should minimize anxiogenic circumstances during early withdrawal because the effects of these stressors may be potentiated during nicotine withdrawal.

\section{ACKNOWLEDGEMENTS}

We thank Mr Richard Sharp for technical assistance and Mr Mike Arends for editorial assistance. This work was supported by National Institute of Mental Health grant MH074697 and the VISN22 Veterans Administration Mental Illness Research and Clinical Core (MAG), Veterans Administration Center for Stress and Mental Health and
MH076850 (VBR), National Institute on Drug Abuse grant DA11946, and Tobacco-Related Disease Research Program grant 15RT-0022 (AM).

\section{DISCLOSURE/CONFLICT OF INTEREST}

SJ and AM declare that, except for income received from their primary employers, no financial support or compensation has been received from any individual or corporate entity over the past 3 years of research or professional service, and they have no personal financial holdings that could be perceived as constituting a potential conflict of interest. VBR declares that over the past 3 years she has received compensation from Addex and San Diego Instruments. MAG declares that over the past 3 years he has received compensation from Abbott, Acadia, Addex, Amgen, AstraZeneca, Bristol-Myers Squibb, Jazz, Organon, Nura, Serono, and Wyeth-Ayerst and holds an equity interest in San Diego Instruments.

\section{REFERENCES}

Acri JB, Brown KJ, Saah MI, Grunberg NE (1995). Strain and age differences in acoustic startle responses and effects of nicotine in rats. Pharmacol Biochem Behav 50: 191-198.

Acri JB, Grunberg NE, Morse DE (1991). Effects of nicotine on the acoustic startle reflex amplitude in rats. Psychopharmacology (Berl) 104: 244-248.

al'Absi M (2006). Hypothalamic-pituitary-adrenocortical responses to psychological stress and risk for smoking relapse. Int J Psychophysiol 59: 218-227.

American Psychiatric Association (1994). American Psychiatric Association, Diagnostic and Statistical Manual of Mental Disorders 4th edn. American Psychiatric Press: Washington, DC.

Beckham JC, Lytle BL, Vrana SR, Hertzberg MA, Feldman ME, Shipley RH (1996). Smoking withdrawal symptoms in response to a trauma-related stressor among Vietnam combat veterans with posttraumatic stress disorder. Addict Behav 21: 93-101.

Brown JS, Kalish HI, Farber IE (1951). Conditioned fear as revealed by magnitude of startle response to an auditory stimulus. $J$ Exp Psychol 41: 317-328.

Bruijnzeel AW, Markou A (2004). Adaptations in cholinergic transmission in the ventral tegmental area associated with the affective signs of nicotine withdrawal in rats. Neuropharmacology 47: 572-579.

Bruijnzeel AW, Zislis G, Wilson C, Gold MS (2007). Antagonism of $\mathrm{CRF}$ receptors prevents the deficit in brain reward function associated with precipitated nicotine withdrawal in rats. Neuropsychopharmacology 32: 955-963.

Chavez-Noriega LE, Crona JH, Washburn MS, Urrutia A, Elliott KJ, Johnson EC (1997). Pharmacological characterization of recombinant human neuronal nicotinic acetylcholine receptors $\mathrm{h} \alpha 2 \beta 2$, $\mathrm{h} \alpha 2 \beta 4, \mathrm{~h} \alpha 3 \beta 2, \mathrm{~h} \alpha 3 \beta 4, \mathrm{~h} \alpha 4 \beta 2, \mathrm{~h} \alpha 4 \beta 4$ and $\mathrm{h} \alpha 7$ expressed in Xenopus oocytes. J Pharmacol Exp Ther 280: 346-356.

Cheeta S, Irvine EE, Kenny PJ, File SE (2001). The dorsal raphe nucleus is a crucial structure mediating nicotine's anxiolytic effects and the development of tolerance and withdrawal responses. Psychopharmacology (Berl) 155: 78-85.

Costall B, Kelly ME, Naylor RJ, Onaivi ES (1989). The actions of nicotine and cocaine in a mouse model of anxiety. Pharmacol Biochem Behav 33: 197-203.

Damaj MI, Kao W, Martin BR (2003). Characterization of spontaneous and precipitated nicotine withdrawal in the mouse. J Pharmacol Exp Ther 307: 526-534. 
Davis M (1989). Sensitization of the acoustic startle reflex by footshock. Behav Neurosci 103: 495-503.

Davis M (1998). Anatomic and physiologic substrates of emotion in an animal model. J Clin Neurophysiol 15: 378-387.

Davis M, Schlesinger LS, Sorenson CA (1989). Temporal specificity of fear conditioning: effects of different conditioned stimulusunconditioned stimulus intervals on the fear-potentiated startle effect. J Exp Psychol Anim Behav Process 15: 295-310.

de Jongh R, Geyer MA, Olivier B, Groenink L (2005). The effects of sex and neonatal maternal separation on fear-potentiated and light-enhanced startle. Behav Brain Res 161: 190-196.

de Jongh R, Groenink L, van Der Gugten J, Olivier B (2002). The light-enhanced startle paradigm as a putative animal model for anxiety: effects of chlordiazepoxide, flesinoxan and fluvoxamine. Psychopharmacology (Berl) 159: 176-180.

de Jongh R, Groenink L, van der Gugten J, Olivier B (2003). Lightenhanced and fear-potentiated startle: temporal characteristics and effects of $\alpha$-helical corticotropin-releasing hormone. Biol Psychiatry 54: 1041-1048.

Epping-Jordan MP, Watkins SS, Koob GF, Markou A (1998). Dramatic decreases in brain reward function during nicotine withdrawal. Nature 393: 76-79.

Frishman WH (2007). Smoking cessation pharmacotherapy: nicotine and non-nicotine preparations. Prev Cardiol 10 (Suppl 1): S10-S22.

Harvey SC, Luetje CW (1996). Determinants of competitive antagonist sensitivity on neuronal nicotinic receptor $\beta$ subunits. J Neurosci 16: 3798-3806.

Hebb AL, Zacharko RM, Dominguez H, Laforest S, Gauthier M, Levac C et al (2003). Changes in brain cholecystokinin and anxiety-like behavior following exposure of mice to predator odor. Neuroscience 116: 539-551.

Helton DR, Modlin DL, Tizzano JP, Rasmussen K (1993). Nicotine withdrawal: a behavioral assessment using schedule controlled responding, locomotor activity, and sensorimotor reactivity. Psychopharmacology (Berl) 113: 205-210.

Helton DR, Tizzano JP, Monn JA, Schoepp DD, Kallman MJ (1997). LY354740: a metabotropic glutamate receptor agonist which ameliorates symptoms of nicotine withdrawal in rats. Neuropharmacology 36: 1511-1516.

Hildebrand BE, Nomikos GG, Bondjers C, Nisell M, Svensson TH (1997). Behavioral manifestations of the nicotine abstinence syndrome in the rat: peripheral versus central mechanisms. Psychopharmacology (Berl) 129: 348-356.

Hughes JR, Gust SW, Skoog K, Keenan RM, Fenwick JW (1991). Symptoms of tobacco withdrawal: a replication and extension. Arch Gen Psychiatry 48: 52-59.

Irvine EE, Cheeta S, File SE (2001). Tolerance to nicotine's effects in the elevated plus-maze and increased anxiety during withdrawal. Pharmacol Biochem Behav 68: 319-325.

Jonkman S, Henry B, Semenova S, Markou A (2005). Mild anxiogenic effects of nicotine withdrawal in mice. Eur J Pharmacol 516: 40-45.

Koch M (1999). The neurobiology of startle. Prog Neurobiol 59: 107-128.

Malin DH, Lake JR, Carter VA, Cunningham JS, Hebert KM, Conrad DL et al (1994). The nicotinic antagonist mecamylamine precipitates nicotine abstinence syndrome in the rat. Psychopharmacology (Berl) 115: 180-184.

Malin DH, Lake JR, Newlin-Maultsby P, Roberts LK, Lanier JG, Carter VA et al (1992). Rodent model of nicotine abstinence syndrome. Pharmacol Biochem Behav 43: 779-784.

Mansbach RS, Geyer MA, Braff DL (1988). Dopaminergic stimulation disrupts sensorimotor gating in the rat. Psychopharmacology (Berl) 94: 507-514.

Palamarchouk VS, Swiergiel AH, Dunn AJ (2002). Hippocampal noradrenergic responses to CRF injected into the locus coeruleus of unanesthetized rats. Brain Res 950: 31-38.
Pandey SC, Roy A, Xu T, Mittal N (2001). Effects of protracted nicotine exposure and withdrawal on the expression and phosphorylation of the CREB gene transcription factor in rat brain. J Neurochem 77: 943-952.

Papke RL, Sanberg PR, Shytle RD (2001). Analysis of mecamylamine stereoisomers on human nicotinic receptor subtypes. $J$ Pharmacol Exp Ther 297: 646-656.

Perkins KA, Grobe JE (1992). Increased desire to smoke during acute stress. Addiction 87: 1037-1040.

Pomerleau CS, Pomerleau OF, McPhee K, Morrell EM (1990). Discordance of physiological and biochemical response to smoking and to psychological stress. Br J Addict 85: 1309-1316.

Pomerleau OF, Pomerleau CS, Mehringer AM, Snedecor SM, Ninowski R, Sen A (2005). Nicotine dependence, depression, and gender: characterizing phenotypes based on withdrawal discomfort, response to smoking, and ability to abstain. Nicotine Tob Res 7: 91-102.

Pudovkina OL, Kawahara Y, de Vries J, Westerink BH (2001). The release of noradrenaline in the locus coeruleus and prefrontal cortex studied with dual-probe microdialysis. Brain Res 906: 38-45.

Rasmussen K, Calligaro DO, Czachura JF, Dreshfield-Ahmad LJ, Evans DC, Hemrick-Luecke SK et al (2000). The novel 5hydroxytryptamine(1A) antagonist LY426965: effects on nicotine withdrawal and interactions with fluoxetine. J Pharmacol Exp Ther 294: 688-700.

Rasmussen K, Czachura JF, Kallman MJ, Helton DR (1996). The CCK-B antagonist LY288513 blocks the effects of nicotine withdrawal on auditory startle. Neuroreport 7 : 1050-1052.

Rasmussen K, Kallman MJ, Helton DR (1997). Serotonin-1A antagonists attenuate the effects of nicotine withdrawal on the auditory startle response. Synapse 27: 145-152.

Risbrough VB, Stein MB (2006). Role of corticotropin releasing factor in anxiety disorders: a translational research perspective. Horm Behav 50: 550-561.

Schweimer J, Fendt M, Schnitzler HU (2005). Effects of clonidine injections into the bed nucleus of the stria terminalis on fear and anxiety behavior in rats. Eur J Pharmacol 507: 117-124.

Semenova S, Bespalov A, Markou A (2003). Decreased prepulse inhibition during nicotine withdrawal in DBA/2J mice is reversed by nicotine self-administration. Eur J Pharmacol 472: 99-110.

Skjei KL, Markou A (2003). Effects of repeated withdrawal episodes, nicotine dose, and duration of nicotine exposure on the severity and duration of nicotine withdrawal in rats. Psychopharmacology (Berl) 168: 280-292.

Walker DL, Davis M (1997). Double dissociation between the involvement of the bed nucleus of the stria terminalis and the central nucleus of the amygdala in startle increases produced by conditioned versus unconditioned fear. J Neurosci 17: 9375-9383.

Walker DL, Davis M (2002). Light-enhanced startle: further pharmacological and behavioral characterization. Psychopharmacology (Berl) 159: 304-310.

Walker DL, Toufexis DJ, Davis M (2003). Role of the bed nucleus of the stria terminalis versus the amygdala in fear, stress, and anxiety. Eur J Pharmacol 463: 199-216.

Watkins SS, Stinus L, Koob GF, Markou A (2000). Reward and somatic changes during precipitated nicotine withdrawal in rats: centrally and peripherally mediated effects. J Pharmacol Exp Ther 292: 1053-1064.

Zvolensky MJ, Feldner MT, Leen-Feldner EW, Gibson LE, Abrams $\mathrm{K}$, Gregor K (2005). Acute nicotine withdrawal symptoms and anxious responding to bodily sensations: a test of incremental predictive validity among young adult regular smokers. Behav Res Ther 43: 1683-1700. 